\title{
Caracterização de matérias-primas cerâmicas do Vale do Rio Caí
}

\author{
(Characterization of ceramic raw materials from the \\ Caí River Valley, RS, Brazil)
}

\author{
J. E. Zorzi, S. G. Echeverregaray, J. V. Emiliano, C. A. Perottoni, R. C. D. Cruz \\ Instituto de Materiais Cerâmicos, Universidade de Caxias do Sul, Bom Princípio, RS, 95765-000, Brasil \\ jezorzi@ucs.br
}

\begin{abstract}
Resumo
Este trabalho tem como objetivo a caracterização química e mineralógica de matérias-primas argilosas utilizadas pelas indústrias cerâmicas do Vale do Rio Caí, RS. Essa região, situada entre Porto Alegre e a Serra Gaúcha, é o maior centro produtor cerâmico para construção civil do estado do Rio Grande do Sul. Apesar da importância da indústria cerâmica para a economia local e do Estado, a grande maioria das argilas disponíveis para consumo nunca foi caracterizada satisfatoriamente e não existem dados técnicos e científicos que possam orientar tanto a correta exploração das jazidas quanto o desenvolvimento de produtos cerâmicos de maior valor agregado. Neste trabalho foram feitas análises por fluorescência e difração de raios X das principais argilas utilizadas pela indústria cerâmica da região. De acordo com o método de análise hierárquica de agrupamentos e tendo como base a composição química das amostras, foram identificados três grupos de matérias-primas: argilas residuais (ou primárias) e dois grupos de argilas transportadas (ou secundárias). A diferenciação das matérias-primas em grupos se manifesta também na composição de fases das amostras, tal como determinada por difração de raios $\mathrm{X}$ e análise racional.
\end{abstract}

Palavras-chave: indústria cerâmica, matérias-primas, caracterização mineralógica, caracterização química.

\begin{abstract}
This work aims to characterize the chemistry and mineralogy of clay raw materials used in the heavy clay industry of the Cai River Valley, in southern Brazil. This region lies between Porto Alegre and Serra Gaúcha and is regarded as the major production center of brick and tiles in the Rio Grande do Sul. Despite the importance of this activity for both the local and state economy, the vast majority of clay raw materials have never been satisfactorily characterized, so there is not adequate data to guide its correct exploitation or to allow the development of ceramic products of higher quality. In this workX-ray fluorescence and diffraction were applied to analyze the clays largely used by the ceramic industry. Three groups of heavy clay were identified based on the hierarchical agglomerative cluster analysis of the samples chemical composition: residual (or primary), and transported (or secondary) clays. This was further verified considering the phase composition of samples, as estimated by X-ray diffraction and rational analysis. Keywords: ceramic industry, raw materials, mineralogical characterization, chemical characterization.
\end{abstract}

\section{INTRODUÇÃO}

A região do Vale do Caí ocupa uma área de aproximadamente $1850 \mathrm{~km}^{2}$ da região nordeste do Rio Grande do Sul, limitada pelas regiões geomorfológicas da depressão periférica ao sul e pelas encostas do planalto meridional ao norte (Fig. 1). Constitui uma região de relevo muito peculiar chamada de rebordo do Planalto das Araucárias, que se estende da porção sul dos patamares da bacia do Paraná até encontrar a depressão gaúcha. Está localizada entre $29^{\circ} 50^{\prime} \mathrm{S}$ e $29^{\circ} 17^{\prime} \mathrm{S}$ de latitude e $51^{\circ} 41^{\prime}$ $\mathrm{O}$ e $51^{\circ} 10^{\prime} \mathrm{O}$ de longitude e regionalmente é denominada Encosta Inferior do Nordeste. A topografia que predomina é a de coxilhas (termo equivalente para colinas e lombas) tanto nas altitudes elevadas do planalto quanto nas baixas altitudes da depressão. A diferenciação destas coxilhas se faz pelo processo de formação dos solos. Enquanto no planalto sua origem é predominantemente basáltica, na depressão possui origem sedimentar e arenítica. Nestas últimas, separando e permeando as coxilhas estão as planícies de alagamento do rio Caí e seus afluentes. A região é de baixa altitude $(50 \mathrm{~m})$ e apresenta relevo plano ou levemente ondulado ao sul, enquanto na região central a altitude média é de até $200 \mathrm{~m}$, com predominância de várzeas, encostas e morros. Ao norte predominam escarpas, vales profundos e elevações com até $500 \mathrm{~m}$ de altitude. O clima da região é temperado subtropical úmido, caracterizado por invernos frios e úmidos e primaveras de temperaturas mais elevadas. O solo é predominantemente composto por argila vermelha com forte acidez natural [1].

$\mathrm{O}$ rio Caí pertence à região hidrográfica do Guaíba. Sua nascente está localizada no planalto gaúcho da Serra Geral, no município de São Francisco de Paula, em cotas que ultrapassam os $800 \mathrm{~m}$ de altitude. Seu curso de água tem 

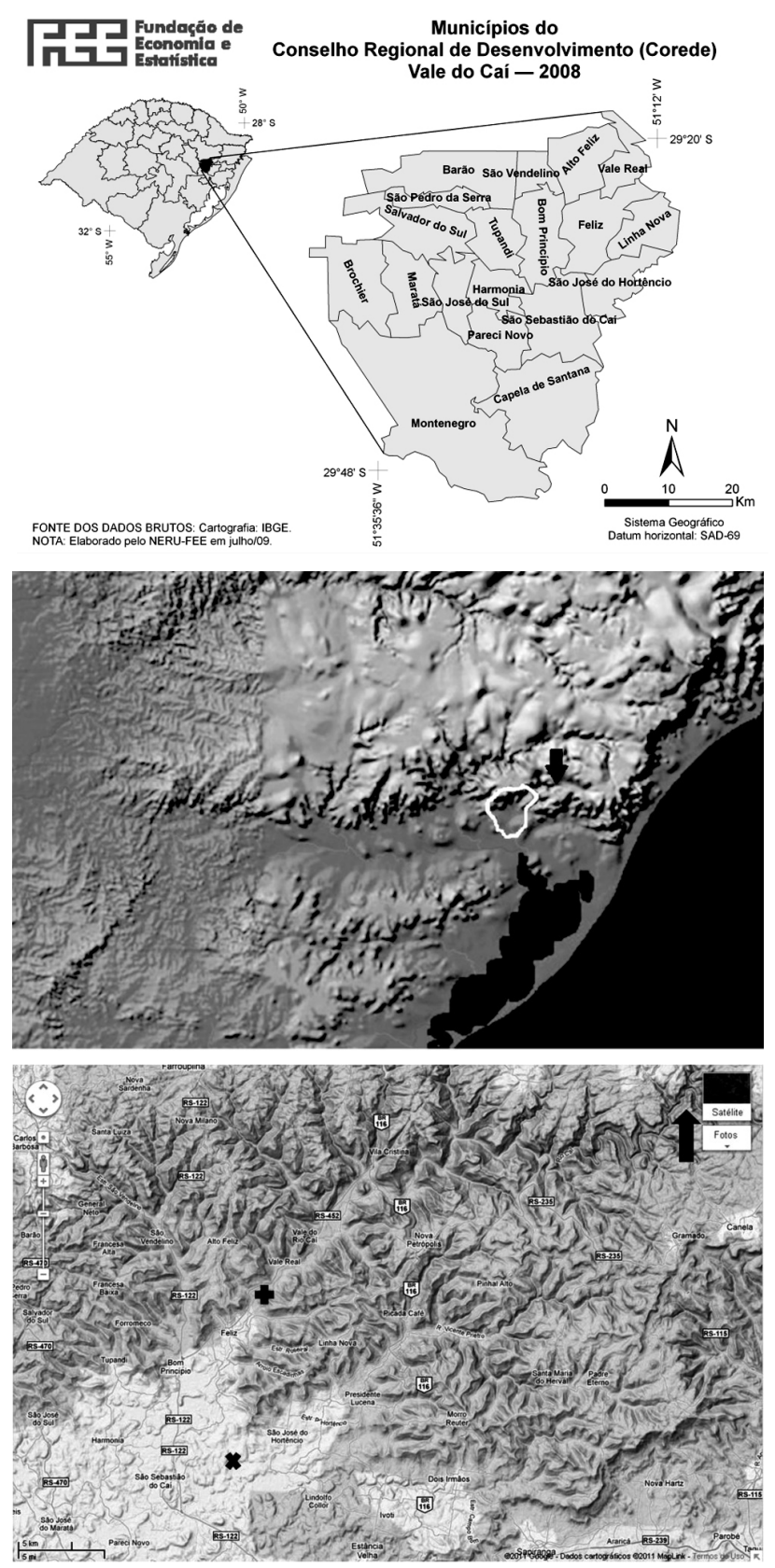

Figura 1: Acima: mapa geopolítico do Estado do Rio Grande do Sul mostrando, no detalhe, os municípios que fazem parte do Conselho Regional de Desenvolvimento (Corede) da região do Vale do Rio Caí [5]. No centro: mapa hidrogeográfico do Rio Grande do Sul, mostrando o Vale do Rio Caí delimitado em branco. A seta aponta para a bacia do Rio Caí [6]. Abaixo: detalhe do mapa hidrogeográfico do vale do Rio Caí. Os símbolos (+) e (x) marcam sítios com a presença de argilas primárias e secundárias, respectivamente. A seta indica a nascente do Rio Caí [7].

[Figure 1: Above: geopolitical map of the Rio Grande do Sul state showing, in the expanded view, the cities that constitute the Conselho Regional de Desenvolvimento (Corede) of the Cai River Valley [5]. At the center: hidrogeographic map of the Rio Grande do Sul state, showing the Cai River Valley delimited in white. The arrow points to the Cai River basin [6]. Below: detail of the hidrogeographic map of the Cai River Valley. The symbols $(+)$ and (x) mark primary and secondary clay sites, respectively. The arrow points to the Cai River headwaters [7].] uma extensão de $285 \mathrm{~km}$ [2]. Sob o aspecto hidrogeológico, a região da nascente do rio Caí tem sua origem nos basaltos da formação Serra Geral, os quais se comportam como um aquífero fraturado, onde a circulação da água se dá através das superfícies de descontinuidade geradas pelas fraturas e falhas existentes $[3,4]$.

O Vale do Rio Caí é o maior centro produtor de materiais cerâmicos para a cadeia da construção civil do Estado do Rio Grande do Sul. Somente o município de Bom Princípio (com aproximadamente 12.000 habitantes) possui 28 indústrias cerâmicas de pequeno e médio porte. Apesar da alta densidade industrial, a grande maioria das reservas de matéria-prima da região nunca foi caracterizada de modo apropriado e não existem dados técnicos e científicos que possam orientar tanto a correta exploração das jazidas quanto o desenvolvimento de produtos cerâmicos de maior valor agregado $[1,5,8,9]$.

Em razão da disponibilidade de argilas de baixa dureza (macias) a indústria cerâmica regional adotou desde o início das suas atividades a tecnologia de fabricação por via semiúmida. Estas argilas são caracterizadas por uma umidade natural acima de $20 \%$ em base úmida, não serem contaminadas com fragmentos de rochas, seixos, torrões muito duros ou outros materiais macroscópicos não argilosos e serem facilmente desagregadas pela ação mecânica de laminadores de baixa potência e caixões alimentadores/misturadores. A opção pela via semiúmida também contém forte viés cultural, uma vez que a região foi ocupada por sucessivas vagas de imigrantes de origem européia, principalmente alemães e italianos, que trouxeram na sua bagagem cultural a tradição da produção de tijolos e telhas com argilas "macias", o tipo de argila predominante na Europa. Apesar dos costumes arraigados, da longa experiência produtiva e da farta disponibilidade de equipamentos de produção por via semiúmida, cabe ressaltar que este processo pode levar a variações dimensionais significativas no produto acabado e, por essa razão, requer a adoção de técnicas de gestão da qualidade mais rigorosas que outros processos (por exemplo, via seca) para garantir a conformidade do produto frente a normas técnicas.

A tecnologia dos equipamentos ora em uso pela maioria dos ceramistas no Vale do Rio Caí, principalmente fornos e secadores, não representa o que há de mais avançado no setor e, conseqüentemente, pode levar a perdas no processo superiores a $30 \%$. Além desta deficiência, a exploração não racional das matérias-primas nas jazidas aponta para ameaças à cadeia produtiva, podendo levar à exaustão prematura das reservas regionais e aumento do custo da tonelada bruta, o que poderá comprometer a sustentabilidade econômica e ambiental da indústria cerâmica local devido à necessidade da exploração de áreas mais distantes [10]. Assim sendo, é premente a elaboração de uma base de dados das argilas existentes, visando o planejamento da atividade da indústria cerâmica do Vale do Rio Caí a médio e longo prazo.

Neste contexto, e contemplando as metas do Projeto Caracterização de Matérias-Primas para a Indústria de Cerâmica Vermelha, executado pela Universidade de 
Caxias do Sul (UCS) no Instituto de Materiais Cerâmicos (IMC), em parceria com a Secretaria de Ciência, Inovação e Desenvolvimento Tecnológico do Estado do Rio Grande do Sul (SCIT-RS) e a Prefeitura Municipal de Bom Princípio, o presente trabalho tem como objetivo a caracterização química e mineralógica das principais argilas utilizadas pela indústria da cerâmica vermelha do Vale do Rio Caí, visando a criação de uma base de dados. Para tanto, amostras de matérias-primas usadas por empresas do Vale do Caí foram caracterizadas por técnicas de fluorescência de raios $\mathrm{X}$ (FRX) e difração de raios X (DRX). A partir dos resultados obtidos as amostras foram classificadas de acordo com um algoritmo de agrupamento hierárquico.

\section{MATERIAIS E MÉTODOS}

As amostras foram coletadas diretamente nas jazidas ou no estoque de argila das indústrias cerâmicas do Vale do Rio Caí e identificadas de acordo com o local de coleta. Após secagem em estufa a $110^{\circ} \mathrm{C}$ por $24 \mathrm{~h}$, as argilas foram desagregadas em almofariz, peneiradas (partículas menores que $0,044 \mathrm{~mm}$ ), quarteadas e encaminhadas para ensaios de difração de raios X e fluorescência de raios X no Laboratório de Análise de Minerais e Rochas - LAMIR, UFPR.

Para as análises de difração de raios $\mathrm{X}$ foram preparadas quatro lâminas por amostra. (i) pó prensado in natura, (ii) pó in natura (iii) pó tratado a $550{ }^{\circ} \mathrm{C}$ e (iv) pó tratado com etilenoglicol (EGL). Para as últimas três lâminas, após quarteamento, $20 \mathrm{~g}$ da amostra em pó foram desagregadas em $200 \mathrm{~mL}$ de água deionizada com adição de $0,5 \mathrm{~g}$ de dispersante (pirofosfato de sódio). As suspensões resultantes foram mantidas em agitação por 5 min e, posteriormente, em repouso por $6 \mathrm{~h}$. As amostras foram coletadas com pipeta a uma profundidade média de $7 \mathrm{~cm}$ da superfície, depositadas sobre lâminas de vidro e secas a temperatura ambiente. Após secagem, as lâminas (ii) de pó in natura,, (iii) as lâminas com amostras calcinadas a $550{ }^{\circ} \mathrm{C}$ por $2 \mathrm{~h}$ e (iv) as lâminas solvatadas com EGL foram utilizadas para análise por difração de raios X. As lâminas com amostra solvatada com EGL receberam até $1 \mathrm{~mL}$ do reagente nas laterais da lâmina e foram mantidas em repouso por $6 \mathrm{~h}$ antes das análises para determinação de argilominerais expansivos. As medidas foram realizadas em um difratômetro de raios X Philips/ Panalytical PW 1830, com radiação Cuk $\alpha(\lambda=1,54056 \AA)$, operando a $40 \mathrm{kV}$ e $30 \mathrm{~mA}$.

Análises químicas semiquantitativas foram realizadas em um espectrômetro de fluorescência de raios X Philips/ Panalytical PW 2400, com tubo de Rh. Para esta análise foram preparadas pastilhas prensadas $(\sim 1961 \mathrm{MPa}$ por 2 min) com $7 \mathrm{~g}$ de amostra e 1,4 g de cera (Hoechst Wachs C38H76N2O), previamente homogeneizadas.

Os resultados da análise química semiquantitativa foram usados como dados de entrada para análise de agrupamentos e componentes principais (PCA), utilizando o software Tanagra $[11,12]$. A análise de agrupamentos foi conduzida de acordo com um algoritmo de análise hierárquica de agrupamentos (HAC), no qual cada amostra é considerada inicialmente como um grupo (cluster) unitário, que é então combinado (aglomerado) com outros grupos, de acordo com a sua similaridade, até que todas as amostras formem um único grupo.

\section{RESULTADOS E DISCUSSÃO}

As matérias-primas do Vale do Rio Caí que constituíram objeto deste estudo são oriundas de (a) depósitos de argilas formados localmente, resultantes da decomposição por intemperismo do basalto da Serra Geral, também conhecidas como argilas de morro - nesse caso, em particular, os morros são mais conhecidos como "coxilhas", (b) depósitos sedimentares formados ao longo do leito do Rio Caí, no qual predominam os produtos de decomposição do basalto e (c) depósitos sedimentares em platôs intermediários da Serra, a aproximadamente $400 \mathrm{~m}$ de altitude, também formados pelos produtos da decomposição das rochas da Serra. No primeiro caso, em se tratando de argilas formadas no mesmo local ocupado originalmente pela rocha-mãe, as mesmas são denominadas argilas residuais ou primárias [13]. No segundo e no terceiro casos, por serem carregadas pela água para a área de sedimentação, são denominadas argilas transportadas ou secundárias [13].

A Tabela I apresenta a composição química (expressa em termos do percentual em massa dos óxidos equivalentes) e perda ao fogo das amostras. A análise HAC sugere que o conjunto de argilas analisado pode ser dividido em três clusters com nove, duas e quatro amostras, respectivamente. Assim, os resultados exibidos na Tabela I foram agrupados em três subconjuntos, nesta mesma seqüência.

Cada argila analisada pode ser representada por um ponto num espaço de nove dimensões, representando o teor de $\mathrm{SiO}_{2}, \mathrm{Al}_{2} \mathrm{O}_{3}, \mathrm{Fe}_{2} \mathrm{O}_{3}, \mathrm{TiO}_{2}, \mathrm{Na}_{2} \mathrm{O}, \mathrm{K}_{2} \mathrm{O}, \mathrm{MgO}, \mathrm{CaO}$ e a perda ao fogo, tais como determinados na análise semiquantitativa por FRX. Na análise de componentes principais, a dimensão do espaço de parâmetros (que possivelmente exibem alguma correlação entre si, como é o caso do teor de metais alcalinos) é reduzida por meio de uma transformação ortogonal a um conjunto de eixos (eixos principais) que retém a maior parte da variância dos resultados. A análise de componentes principais da composição química das argilas resultou em três componentes que explicam $96 \%$ da variância dos resultados. A Fig. 2 ilustra a clara separação das matérias-primas em três grupos (tal como sugerido pela análise hierárquica de agrupamentos), em um gráfico cujos eixos correspondem aos três componentes principais. Cada um desses eixos é definido como uma combinação linear dos percentuais em massa de cada elemento presente nas matérias-primas.

A distinção entre as argilas também pode ser apreciada na Fig. 3, que apresenta o teor de $\mathrm{Na}_{2} \mathrm{O}$ em função do conteúdo de $\mathrm{Al}_{2} \mathrm{O}_{3}$, as espécies químicas de maior e menor facilidade de lixiviação, respectivamente. Observa-se que o primeiro grupo de argilas apresenta o maior teor de alumínio. Além disso, percebe-se claramente o aumento no teor de sódio do primeiro para o terceiro grupo de argilas, de acordo com a 
Tabela I - Composição química (expressa em percentual de massa do óxido correspondente) e perda ao fogo das amostras agrupadas de acordo com a análise hierárquica de agrupamentos.

[Table I - Chemical composition (expressed in terms of weight percent of the corresponding oxide) and loss on ignition for the samples grouped according to the hierarchical clustering algorithm.]

\begin{tabular}{|c|c|c|c|c|c|c|c|c|c|}
\hline Sigla & $\mathrm{SiO}_{2}$ & $\mathrm{Al}_{2} \mathrm{O}_{3}$ & $\mathrm{Fe}_{2} \mathrm{O}_{3}$ & $\mathrm{TiO}_{2}$ & $\mathrm{Na}_{2} \mathrm{O}$ & $\mathrm{K}_{2} \mathrm{O}$ & $\mathrm{MgO}$ & $\mathrm{CaO}$ & P.F. \\
\hline 0003-11 & 52,4 & 24,7 & 10,0 & 1,5 & 0,0 & 0,3 & 0,1 & 0,0 & 10,7 \\
\hline 0004-11 & 42,0 & 30,1 & 12,2 & 0,9 & 0,0 & 0,0 & 0,2 & 0,0 & 14,2 \\
\hline 0005-11 & 41,8 & 30,3 & 13,0 & 0,6 & 0,0 & 0,0 & 0,1 & 0,0 & 13,7 \\
\hline 0006-11 & 40,6 & 28,4 & 15,8 & 2,2 & 0,0 & 0,0 & 0,3 & 0,0 & 12,4 \\
\hline 0011-11 & 42,7 & 27,2 & 14,1 & 2,2 & 0,0 & 0,1 & 0,3 & 0,0 & 13,0 \\
\hline 0012-11 & 49,2 & 27,4 & 9,9 & 0,9 & 0,0 & 0,1 & 0,1 & 0,0 & 12,0 \\
\hline 0013-11 & 49,5 & 26,7 & 10,2 & 1,0 & 0,0 & 0,1 & 0,1 & 0,0 & 12,1 \\
\hline 0014-11 & 44,9 & 28,6 & 11,5 & 1,2 & 0,0 & 0,0 & 0,2 & 0,0 & 13,2 \\
\hline 0015-11 & 46,2 & 25,2 & 14,4 & 1,2 & 0,0 & 0,4 & 0,4 & 0,0 & 11,9 \\
\hline Média & 45,5 & 27,6 & 12,3 & 1,3 & $\mathbf{0 , 0}$ & 0,1 & 0,2 & $\mathbf{0 , 0}$ & 12,6 \\
\hline 0019-11 & 55,0 & 16,5 & 15,6 & 1,9 & 0,1 & 0,4 & 0,4 & 0,3 & 9,6 \\
\hline 0020-11 & 60,1 & 14,3 & 13,3 & 3,0 & 0,1 & 0,5 & 0,3 & 0,1 & 8,0 \\
\hline Média & 57,6 & 15,4 & 14,5 & 2,5 & 0,1 & 0,5 & 0,4 & 0,2 & 8,8 \\
\hline 0002-11 & 60,6 & 15,0 & 8,4 & 1,6 & 0,6 & 0,9 & 0,8 & 0,7 & 10,8 \\
\hline 0009-11 & 56,6 & 16,5 & 10,5 & 1,8 & 0,6 & 1,0 & 0,9 & 0,9 & 10,6 \\
\hline 0016-11 & 50,4 & 18,0 & 14,3 & 1,7 & 0,6 & 1,0 & 1,2 & 1,3 & 10,6 \\
\hline 0021-11 & 51,5 & 16,9 & 14,0 & 1,8 & 0,7 & 1,2 & 1,4 & 1,5 & 10,2 \\
\hline Média & 54,8 & 16,6 & 11,8 & 1,7 & 0,6 & 1,0 & 1,1 & 1,1 & 10,5 \\
\hline
\end{tabular}

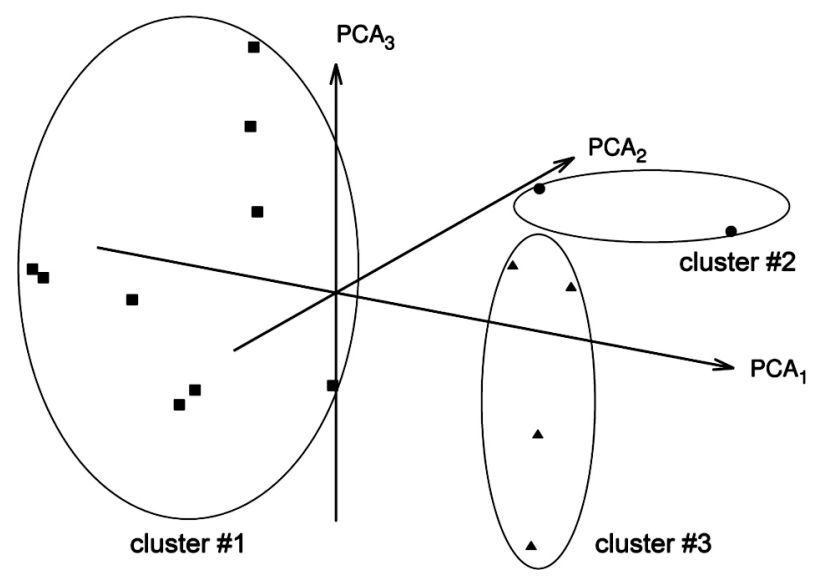

Figura 2: Gráfico de componentes principais exibindo a disposição dos três conjuntos de argilas identificados na análise hierárquica de agrupamentos.

[Figure 2: Principal components plot showing the three clusters of clays identified by the hierarchical agglomerative cluster algorithm.]

tendência esperada para a transição de argilas primárias para secundárias.

O resultado da análise de agrupamentos baseada na composição química das argilas apresenta uma excelente correlação com a natureza das argilas. De fato, o primeiro e o terceiro grupos são constituídos por argilas primárias e secundárias, respectivamente. $\mathrm{O}$ segundo grupo, com

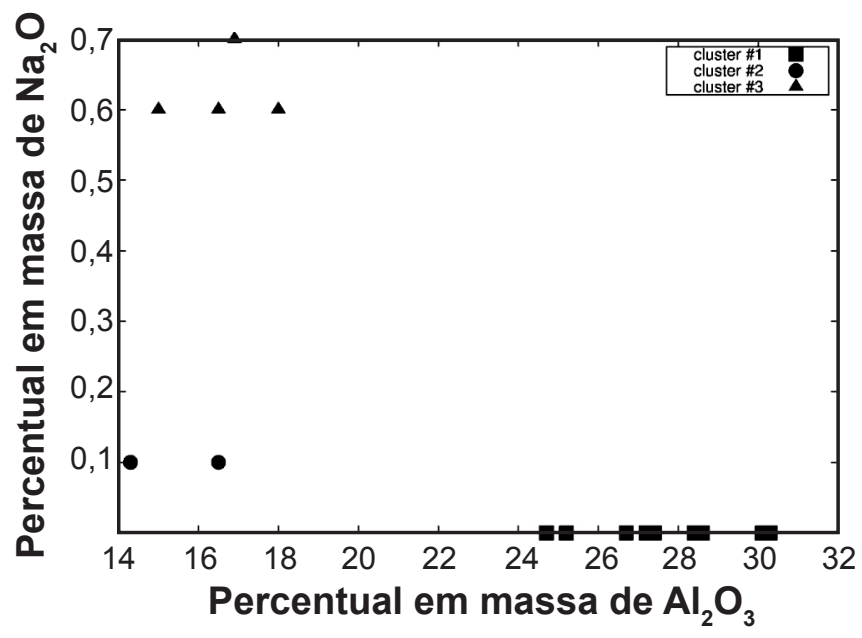

Figura 3: Percentual em massa de óxido de sódio e de alumínio nos três grupos de argilas identificados pela análise hierárquica de agrupamentos.

[Figure 3: Weight percent of sodium and aluminum oxide in the three clusters of clays identified in the hierarchical agglomerative cluster analysis.]

duas matérias-primas, corresponde a argilas coletadas de depósitos sedimentares situados a aproximadamente $400 \mathrm{~m}$ acima do nível do mar, em platô intermediário entre o topo e a base da Serra. É importante ressaltar que a procedência das matérias-primas não foi utilizada na análise hierárquica de agrupamentos dos dados de composição química. Portanto, a 
análise de agrupamentos permitiu a identificação da origem das matérias-primas com base apenas na análise química semiquantitativa por fluorescência de raios X.

Uma melhor compreensão das diferenças entre as argilas que compõem cada um dos grupos acima identificados advém da composição de fases, resultante da caracterização mineralógica. A Fig. 4 apresenta um difratograma típico das argilas primárias, com a identificação dos picos de Bragg associados a cada uma das fases majoritárias presentes na amostra. A presença de quartzo, caulinita, rutilo/anatásio

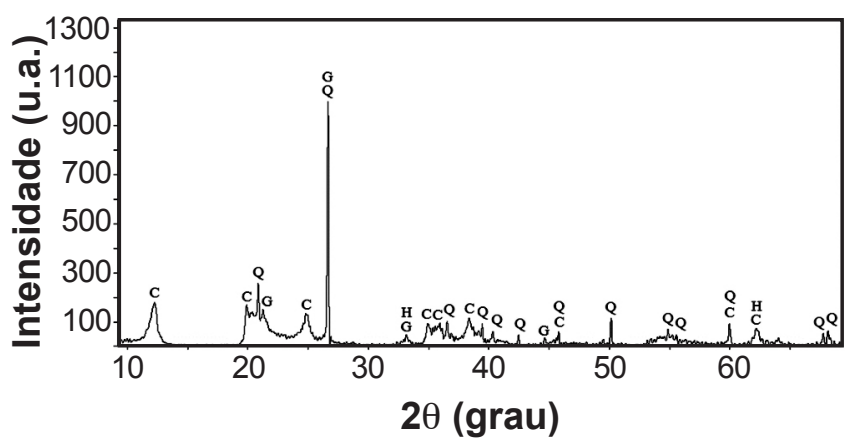

Figura 4: Difratograma de uma argila primária do Vale do Rio Caí - amostra in natura. Os picos de Bragg associados a cada fase presente na amostra são identificados como Q (quartzo), C (caulinita), H (hematita) e G (goethita).

[Figure 4: X-ray diffraction pattern of a primary clay from the Cai River Valley - sample in natura. The Bragg peaks assigned to each phase present in the sample are identified as $Q$ (quartz), $C$ (kaulinite), H (hematite) and $G$ (goethite).]
Tabela II - Composição química dos minerais usados como referência para a análise racional [18].

[Table II - Chemical composition of the minerals used as reference for the rational analysis [18].]

\begin{tabular}{cc}
\hline Matérias-Primas & Fórmula Teórica \\
\hline Caulinita & $\mathrm{Al}_{2} \mathrm{O}_{3} \cdot 2 \mathrm{SiO}_{2} \cdot 2 \mathrm{H}_{2} \mathrm{O}$ \\
Mica (muscovita) & $(\mathrm{Na}, \mathrm{K})_{2} \mathrm{O} \cdot 3 \mathrm{Al}_{2} \mathrm{O}_{3} \cdot 6 \mathrm{SiO}_{2} \cdot 2 \mathrm{H}_{2} \mathrm{O}$ \\
Quartzo & $\mathrm{SiO}$ \\
Feldspato alcalino & $(\mathrm{Na}, \mathrm{K})_{2} \mathrm{O} \cdot \mathrm{Al}_{2} \mathrm{O}_{3} \cdot 6 \mathrm{SiO}_{2}$ \\
Plagioclásio (andesina) & $\mathrm{Na}_{2} \mathrm{O} \cdot 2 \mathrm{CaO} \cdot 3 \mathrm{Al}_{2} \mathrm{O}_{3} \cdot 10 \mathrm{SiO}_{2}$ \\
Hematita & $\mathrm{Fe}_{2} \mathrm{O}_{3}$ \\
Rutilo/anatásio & $\mathrm{TiO}_{2}$ \\
\hline
\end{tabular}

e hematita/goethita foi observada em amostras de argilas primárias e secundárias. Por outro lado, ilita/muscovita foi observada apenas nas amostras de argilas primárias, enquanto plagioclásio, feldspato alcalino e argilominerais expansivos (que dão origem a um pico de Bragg em torno de $5^{\circ}(2 \theta)$ nas amostras solvatadas com etilenoglicol) foram observados apenas em amostras de argilas secundárias [14].

Tendo por base os minerais identificados por DRX e a composição química das amostras determinada por FRX, uma análise racional foi realizada com o objetivo de quantificar, mesmo que aproximadamente, o percentual em massa de cada fase presente nas amostras [15-17]. A análise racional baseou-se na composição dos minerais identificados nas amostras, tal como resumida na Tabela II. O resultado da análise racional das matérias-primas se encontra na Tabela III. As amostras cuja totalização das fases cristalinas mais se

Tabela III - Composição de fases das argilas.

[Table III - Clays' phase composition.]

\begin{tabular}{lcccccccc}
\hline Amostra & Plagioclásio & $\begin{array}{c}\text { Feldspato } \\
\text { alcalino }\end{array}$ & Mica & Caulinita & Quartzo & Hematita $^{\text {a }}$ & $\begin{array}{c}\text { Rutilo/ } \\
\text { Anatásio }\end{array}$ & TOTAL \\
\hline $0003-11$ & - & - & 2,5 & 60,1 & 23,3 & 10,0 & 1,5 & 97,4 \\
$0004-11$ & - & - & 0,0 & 76,2 & 6,6 & 12,2 & 0,9 & 95,9 \\
$0005-11$ & - & - & 0,0 & 76,7 & 6,1 & 13,0 & 0,6 & 96,4 \\
$0006-11$ & - & - & 0,0 & 71,9 & 7,2 & 15,8 & 2,2 & 97,1 \\
$0011-11$ & - & - & 0,9 & 68,0 & 10,7 & 14,1 & 2,2 & 95,9 \\
$0012-11$ & - & - & 0,9 & 68,5 & 17,0 & 9,9 & 0,9 & 97,2 \\
$0013-11$ & - & - & 0,9 & 66,8 & 18,1 & 10,2 & 1,0 & 97,0 \\
$0014-11$ & - & - & 0,0 & 72,4 & 11,2 & 11,5 & 1,2 & 96,3 \\
$0015-11$ & - & - & 3,3 & 60,5 & 16,5 & 14,4 & 1,2 & 95,9 \\
Média & - & - & 1,0 & 69,0 & 13,0 & 12,3 & 1,3 & 96,6 \\
$0019-11$ & 2,8 & 1,9 & - & 39,0 & 38,4 & 15,6 & 1,9 & 99,7 \\
$0020-11$ & 1,0 & 3,1 & - & 34,1 & 42,6 & 13,3 & 3,0 & 97,2 \\
Média & 1,9 & 2,5 & - & 36,6 & 40,5 & 14,5 & 2,5 & 98,5 \\
$0002-11$ & 6,7 & 6,6 & - & 30,1 & 38,8 & 8,4 & 1,6 & 92,2 \\
$0009-11$ & 8,7 & 6,5 & - & 32,5 & 32,7 & 10,5 & 1,8 & 92,7 \\
$0016-11$ & 12,5 & 5,3 & - & 34,2 & 24,4 & 14,3 & 1,7 & 92,2 \\
$0021-11$ & 14,4 & 6,4 & - & 29,5 & 25,9 & 14,0 & 1,8 & 92,0 \\
Média & 10,6 & 6,2 & - & 31,6 & 30,5 & 11,8 & 1,7 & 92,4 \\
\hline
\end{tabular}

${ }^{a}$ Parte do óxido de ferro encontra-se na forma de goethita. 
afastou de $100 \%$ foram precisamente as argilas secundárias que apresentaram na sua composição argilominerais expansivos, que não foram levados em conta na análise racional. Nas argilas secundárias de várzea, nas quais o teor de magnésio é mais elevado, há indícios da presença de augita $\left(\mathrm{Ca}(\mathrm{Mg}, \mathrm{Fe}) \mathrm{Si}_{2} \mathrm{O}_{6}\right)$, produto da decomposição do basalto.

As fases cristalinas identificadas na caracterização mineralógica são coerentes com os produtos esperados do processo de decomposição das rochas básicas e ácidas da região [19]. Todas as argilas, independentemente da sua origem, tem como denominador comum a presença da caulinita, o que também está de acordo com o processo de formação dos solos da região a partir das rochas da Serra Geral [19].

Se agruparmos as argilas de acordo com a sua origem (que coincide com o resultado da análise HAC da composição química das amostras), torna-se evidente a elevada homogeneidade mineralógica entre as argilas dos diferentes grupos, porém com maior complexidade mineralógica para o grupo das argilas secundárias. Uma vez mais podemos atribuir essas características aos diferentes processos de formação de cada tipo de argila. Enquanto as argilas primárias originadas nas coxilhas da Depressão Central, próximas à encosta da Serra Geral, perderam as espécies químicas de maior mobilidade ( $\mathrm{Na}, \mathrm{K}, \mathrm{Ca}$ e $\mathrm{Mg}$ ) por lixiviação e não apresentam qualquer indício da presença de feldspatos, as argilas secundárias formadas ao longo do Rio Caí os contém em quantidade e diversidade apreciáveis.

\section{CONCLUSÕES}

Um conjunto de 15 amostras, representativo das matérias-primas utilizadas pelas empresas cerâmicas do Vale do Rio Caí, foi caracterizado do ponto de vista da sua composição química e mineralógica. A análise hierárquica de agrupamentos sugere que este conjunto de amostras pode ser dividido em três grupos, de nove, duas e quatro amostras, respectivamente. O grupo de nove amostras contém amostras de argilas primárias. Os grupos de duas e quatro amostras são formados por argilas secundárias coletadas em platôs intermediários da Serra e ao longo do leito do Rio Caí, respectivamente. A distinção entre estes três grupos se manifestou, também, na composição de fases presentes na amostra, tal como determinada por difração de raios X e análise racional. Os resultados demonstram a utilidade da aplicação de técnicas de mineração de dados (data mining) na classificação de matérias-primas para a indústria cerâmica, tendo por base apenas a análise química semiquantitativa por fluorescência de raios X. Em uma segunda etapa deste trabalho, amostras dos três grupos identificados pela análise HAC serão avaliadas por meio de ensaios mecânicos e térmicos, com o objetivo de verificar em que medida as diferenças observadas na composição química e mineralógica irão influenciar as propriedades de interesse tecnológico destas argilas.

\section{AGRADECIMENTOS}

Este trabalho foi parcialmente financiado pela Universidade de Caxias do Sul (UCS), Secretaria de Ciência, Inovação e Desenvolvimento Tecnológico (SCITRS) e Conselho Nacional de Pesquisa e Desenvolvimento (CNPq). Os autores agradecem às empresas do Vale do Caí pelas argilas usadas neste trabalho e aos funcionários e bolsistas do Instituto de Materiais Cerâmicos (IMC/UCS) que contribuíram com este trabalho.

\section{REFERÊNCIAS}

[1] CODEVARC, Planejamento Estratégico Regional do Vale do Caí - 2010/2014. 1ª Ed., Gráfica e Livraria Dominó, São Sebastião do Caí - RS (2010).

[2] Fundação Estadual de Proteção Ambiental Henrique Luiz Roessler. Disponível em http://www.fepam.rs.gov.br/ qualidade/qualidade cai/cai.asp. Acesso em 11/10/2011.

[3] A. Hausman, Províncias Hidrogeológicas do Rio Grande do Sul. Acta Geológica Leopoldensia, Série Mapas, S. Leopoldo, RS (1995).

[4] Conselho de Recursos Hídricos do Rio Grande do Sul, Avaliação Qualiquantitativa das Disponibilidades e Demandas de Água na Bacia Hidrográfica do Sistema Taquari-Antas, Vol. 1 - Memorial Descritivo, Tomo 1. Porto Alegre: Magna Engenharia (1997) 301 p.

[5] Fundação de Economia e Estatística Siegfried Emanuel Heuser - FEE. Municípios do Conselho Regional de Desenvolvimento (Corede) Vale do Caí. Porto Alegre (2008). Disponível em: <http://mapas.fee.tche.br/wp-content/ uploads/2009/08/corede_vale_do_cai_2008_municipios. png>. Acesso em: 29/06/2011.

[6] HidroSHEDS - U.S. Geological Survey. Disponível em: http://hydrosheds.cr.usgs.gov. Acesso em: 11/10/2011.

[7] Googlemaps - Dados cartográficos (C) 2011. Disponível em http://maps.google.com.br/maps? $\mathrm{q}=$ ri o $+\mathrm{ca} \% \mathrm{C} 3 \% \mathrm{AD} \& \mathrm{hl}=\mathrm{pt}-\mathrm{BR} \& \mathrm{ie}=\mathrm{UTF} 8 \& 1 \mathrm{l}=$ $29.542996,-51.354904 \& \mathrm{spn}=0.510753,1.056747 \& \mathrm{t}=\mathrm{p} \& \mathrm{z}=1$ $1 \&$ vpsrc $=6$, acesso em 17/10/2011.

[8] I. S. S. dos Santos, N. I. W. da Silva, H. J. Wildner, M. Boff, Anais $39^{\circ}$ Cong. Bras. Ceram., Águas de Lindóia, SP (1995) 407.

[9] R. R. Menezes, G. A. Neves, H. C. Ferreira, Cerâmica 47, 302 (2001) 77-81.

[10] J. A. Costa, A. S. Mexias, M. E. B. Gomes, Cerâmica 56, 340 (2010) 360-367.

[11] R. Rakotomalala, Tanagra: un logiciel gratuit pour l'enseignement et la recherche, In Actes de EGC'2005, RNTI-E-3, Vol. 2 (2005) 697-702.

[12] M. Berthold, D. J. Hand (Eds.), Intelligent Data Analysis, $2^{\mathrm{a}}$ Ed. Springer, Berlin, Alemanha (2007) 121.

[13] P. Souza Santos, Ciência e Tecnologia de Argilas, $2^{a}$ Ed., Vol. 1, Edgar Blucher, S. Paulo, SP (1989) 83.

[14] D. M Moore, R. C. Reynolds Jr., X-ray Diffraction and the Identification and Analysis of Clay Minerals, $2^{\text {nd }}$ Ed., Oxford University Press, NY, EUA (1997). 
[15] H. S. Washington, J. Am. Ceram. Soc. 1, 6 (1918) 405421.

[16] C. Coelho, N. Roqueiro, D. Hotza, Mater. Lett. 52, 6 (2002) 394-398.

[17] W. R. Boakes, Ceram. Eng. Sci. Proc. 16, 3 (1995) 9-14. [18] J. W. Anthony, R. A. Bideaux, K. W. Bladh, M. C. Nichols (Eds.), Handbook of Mineralogy, Vol. 2 (Silica, silicates), Mineralogical Society of America, Chantilly, VA 20151-1110, USA. Disponível em http://www. handbookofmineralogy.org. Acesso em 13/10/2011. [19] F. de Araújo Pedron, "Mineralogia, Morfologia e Classificação de Saprolitos e Neossolos Derivado de Rochas Vulcânicas no Rio Grande do Sul”, Tese Dr., Programa de Pós-Graduação em Ciências do Solo, UFSM (2007).

(Rec. 18/10/2011, Rev. 26/01/2012, Ac. 16/03/2012) 